\title{
Vulval angiomyxoma: a case report
}

\section{Sujata Misra ${ }^{1 *}$, Tanushree Sandipta Rath ${ }^{1}$, B. L. Nayak ${ }^{2}$, Sushil Kumar Giri²}

\author{
${ }^{1}$ Department of Obstetrics and Gynecology, SCB Medical College, Cuttack, Odisha, India \\ ${ }^{2}$ Department of Gynaec-oncology, Acharya Harihara Regional Cancer Center, Cuttack, Odisha, India
}

Received: 26 May 2017

Accepted: 24 June 2017

\section{* Correspondence:}

Dr. Sujata Misra,

E-mail: drsujatamisra@gmail.com

Copyright: (c) the author(s), publisher and licensee Medip Academy. This is an open-access article distributed under the terms of the Creative Commons Attribution Non-Commercial License, which permits unrestricted non-commercial use, distribution, and reproduction in any medium, provided the original work is properly cited.

\begin{abstract}
Aggressive angiomyxoma is a rare, locally invasive mesenchymal tumor occurring usually in women of reproductive age, which carries a high risk for local relapse; hence it needs to be differentiated from other mesenchymal tumors occurring in this region. We describe a case of a 39-year-old female presenting with a large swelling on the left labia majora. Initially she presented as a small mass over left labia majora 2 years ago from which biopsy was taken which came as acute inflammatory (suppurative) lesion on histopathological report.

Now she presented with a mass of $14 \times 10 \mathrm{~cm}$ over left labia majora, left perineal region, protruding into the left vaginal wall as well. Clinical examination revealed mass over vulvo-perineal region with variegated appearance and soft to firm in consistency. On per vaginum examination, the mass was extending upto the level of ischiorectal fossa. FNAC of the mass was done and the cytological report came out to be fibrolipoma. In view of benign nature of huge mass, the patient was planned for excision. Gross examination of specimen showed tumour dimensions of $30 \mathrm{~cm} \times 14$ $\mathrm{cm} \times 10 \mathrm{~cm}$. Final histopathology revealed it to be a case of Aggressive Angiomyxoma.
\end{abstract}

Keywords: Aggressive angiomyxoma, Mesenchymal tumor, Perineal aggressive angiomyxomas, Vulval angiomyxoma, Vulvovaginal mesenchymal neoplasm

\section{INTRODUCTION}

Aggressive angiomyxoma (AA) is a slow-growing vulvovaginal mesenchymal neoplasm with a marked tendency for local recurrence, but with a low tendency to metastasize. AA was first described by Steeper and Rosai in 1983.

It usually presents as a vulval polyp and is diagnosed on histopathology. Estrogen and progesterone receptors are commonly found in AA. ${ }^{2}$ It is thus likely to grow during pregnancy and respond to hormonal manipulation. It mainly involves the pelvis, vulva, perineum, vagina and urinary bladder in adult women in the reproductive age. Considering its locally aggressive nature, appropriate management and long-term follow-up is necessary. Many options for the treatment of recurrences have been tried with varying success, but no single modality is clearly beneficial over others.

\section{CASE REPORT}

A 39 years old female presented in the OPD with a huge mass in her vulvo-perineal region (Figure 1) which was gradually increasing in size since, 2 years. Initially she presented with a small mass over her left labia major 2 years back, from which biopsy was taken and which came as acute inflammatory (suppurative) lesion in HP report. Clinical examination revealed mass of size $14 \times 10$ $\mathrm{cm}$ over vulvo-perineal region, with variegated appearance, soft to firm consistency, non-tender with restricted mobility. On PV examination, it was found that mass was extending upto the level of ischiorectal fossa. Rectal mucosa was free on PR examination. 
Routine laboratory investigation reports were within normal limits. FNAC (fine needle aspiration cytology) shows features of few groups of spindle cells over a matrix with lipid background indicating it to be Fibrolipoma.

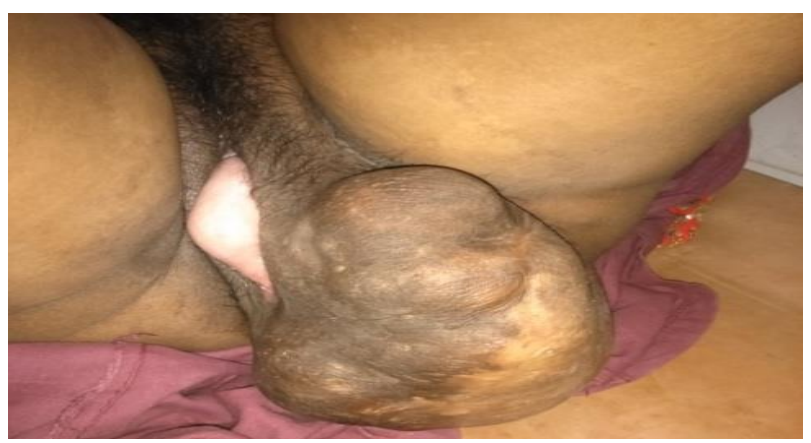

Figure 1: A huge mass in vulvo-perineal region.

Excision of the mass was planned. An elliptical incision was given between labia majora and perineal region. During dissection, the mass was found extending up to ischio-rectal fossa postero-laterally, apex of left lateral fornix superiorly and left vaginal wall medially. It was resected out along the line of cleavage. Gross examination of specimen showed tumour measuring 30 $\mathrm{cm} \times 14 \mathrm{~cm} \times 10 \mathrm{~cm}$ (Figure 2).

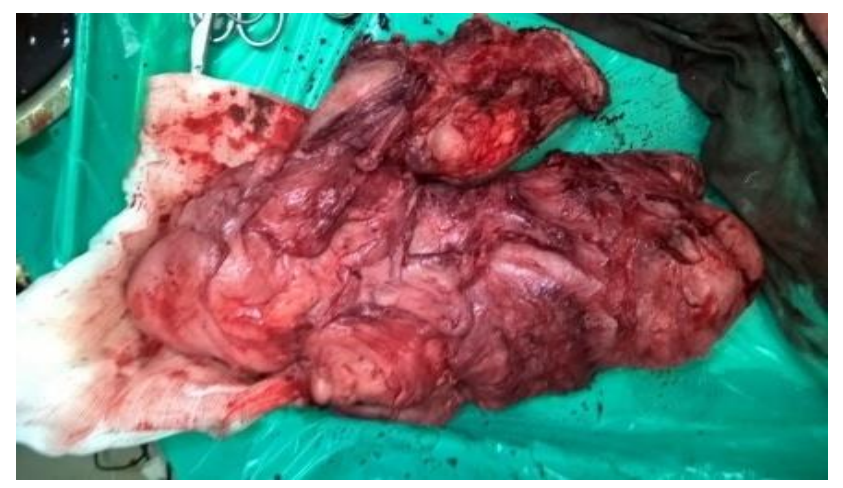

Figure 2: Cut Section showing $30 \mathrm{~cm} \times 14 \mathrm{~cm} \times 10 \mathrm{~cm}$.

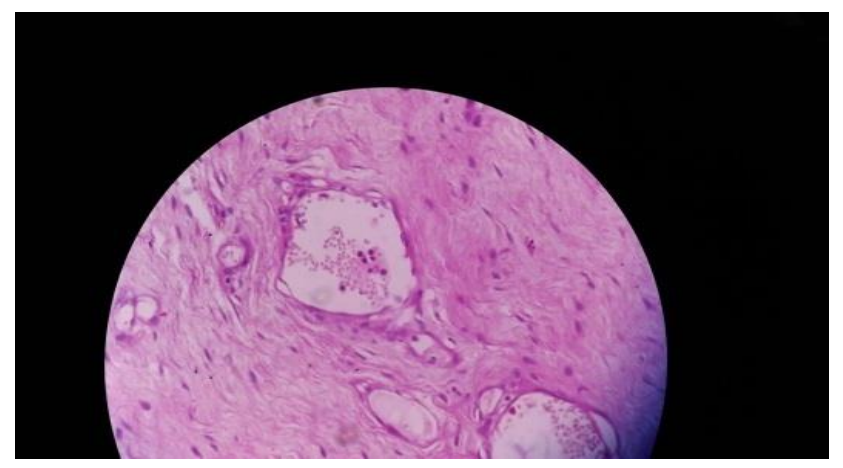

Figure 3: Under high power field histopathology showed dilated blood vessels which are hyalinised. Spindle cells have delicate cytoplasmic process in each end, in a myxoid background.
Cut section showed irregular fibro-fatty tissue with thick walled vessels. Post -operative period was uneventful. Histopathology examination of the mass revealed the mass as aggressive angiomyxoma (Figure 3).

\section{DISCUSSION}

First described in 1983 by Steeper and Rosai perineal aggressive angiomyxomas (AA) are rare mesenchymal tumours. ${ }^{1}$ Angiomyxomas are classified either as superficial (also called as cutaneous myxoma) or aggressive angiomyxomas (AA). Superficial angiomyxomas usually present in middle-aged adults as a single nodule or a polypoidal lesion in the head and neck region that may be clinically confused with skin tag or neurofibroma. The stroma is mostly edematous with little myxoid material. On the other hand, AA occurs almost exclusively in the pelvic and perineal regions of women of reproductive age, but is occasionally reported in men (male-to-female ratio 1:6). ${ }^{2}$ There are at least 150 reported cases in the medical literature, the vast majority of which afflict premenopausal females in their $3^{\text {rd }}$ and $4^{\text {th }}$ decades of life. ${ }^{3,4}$ The case in discussion belongs to this group. The term "aggressive" refers to the locally infiltrative nature of this lesion and its tendency to recur. ${ }^{5}$ Although slow growing, they may attain large sizes (up to $60 \mathrm{~cm}$ ) but are usually $10-20 \mathrm{~cm}$ in their greatest diameter and have a marked tendency to recur locally (up to $72 \%$ ), even decades after resection. ${ }^{3-5}$ In our case it was also a huge mass of size $30 \mathrm{~cm} \times 14 \mathrm{~cm} \times 10 \mathrm{~cm}$ (Figure 2 , Figure 3 ). Usually, this tumor is non-metastasizing, but there are reports of multiple metastases in women treated initially by excision and who later succumbed to metastatic disease. ${ }^{6}$ AA has been reported to invade pelvic organs and bone; however, they typically exert a mass effect and displace normal tissues. ${ }^{4}$

On gross examinations, these tumors are characteristically soft, bulky masses with a smooth external surface, and exhibit a gelatinous appearance on cut section. ${ }^{3}$ Histologic examination shows a sparsely cellular tumor composed of pale to eosinophilic stroma studded with numerous haphazardly arranged blood vessels that stand out against the myxoid background and range in size from thin-walled capillaries and venules to larger muscular arteries (Figure 5). The stroma is distinctly myxoid with intermixed, wispy collagen fibrils; scattered, smooth muscle bundles; and extravasated erythrocytes. $^{7,8}$ Immunohistochemically, most AA express different combinations of estrogen and progesterone receptors, vimentin, desmin, smooth-muscle actin, muscle-specific actin, CD34, and CD44, but all are invariably negative for S-100, CEA, and keratin. ${ }^{3,4}$ Cytogenetic and molecular analysis revealed clonal karyotypic abnormalities including chromosomal translocation involving chromosome 12 associated with rearrangement of the HMGIC gene and it was proposed that AA molecularly belonged to the benign group of mesenchymal tumors showing multiple aberration region involvement. HMGIC expression in aggressive 
angiomyxoma is of value in the distinction of difficult cases from its histological mimics. Several imaging modalities have been used in identifying and describing AA. Sonography usually reveals a hypoechoic or cystic mass. ${ }^{8}$ CT scan typically reveals a tumor with welldefined margins with attenuation less than that of muscle, likely related to the loose myxoid stroma and high-water content of this tumor. ${ }^{8}$ Relative to muscle signals on magnetic resonance (MR) imaging, AA shows an isointense signal on T1-weighted images and a hyperintense one on T2-weighted images. ${ }^{8}$ Angiography typically shows a hypervascular mass. ${ }^{3,4,8}$

Our patient was not subjected to radiological investigation as its clinical appearance at presentation was that of a benign mass. Wide surgical excision is the traditional treatment of choice. Clinically, AA may be misdiagnosed as Bartholin cyst, lipoma, labial cyst, Gartner duct cyst, levator hernia or sarcoma. Fibroepithelial stromal polyp, superficial angiomyxoma, angiomyofibroblastoma, cellular angiofibroma and smooth muscle tumors also need to be considered in the differential diagnoses of a polypoidal mass in the perineum. ${ }^{4,8}$

The first line of therapy for AA is surgery, although achieving negative resection margins is difficult because of the infiltrative nature of the tumor and the absence of a defined capsule. Smaller, more-superficial tumors of the vulva or vagina may be removed with wide, local excision, but larger, deep-seated tumors of the pelvis may require more extensive surgery with partial or complete resection of some pelvic organs, conferring a higher risk of morbidity. ${ }^{7}$ Even though complete surgical resection is the desired goal, incomplete removal is acceptable when significant operative morbidity is anticipated or when preservation of fertility is a concern.

Radiation therapy and chemotherapy are considered lesssuitable options due to low mitotic activity. Radiation therapy has also been used to treat several cases of tumor recurrence with reported tumor-free intervals of 2 to 3 years. A newer approach to the treatment of AA involves hormonal therapy. Given that the tumor occurs primarily in premenopausal women and is positive for estrogen receptor and progesterone receptor, estrogen and progesterone may play a role in its development. In one patient, a vulvar AA was discovered during the first trimester of pregnancy and progressively increased in size throughout the pregnancy. ${ }^{9}$ Several case reports using a gonadotropin-releasing hormone agonist as medical management for AA showed complete radiographic resolution of the tumor. ${ }^{10}$ Although surgery remains the standard of care, the medical treatment of AA with a gonadotropin releasing hormone agonist in the primary or adjuvant setting may offer an alternative to radical surgery. ${ }^{10}$

\section{CONCLUSION}

We conclude that AA is a rare, benign mesenchymal tumor occurring in young females of reproductive age group and is quite site specific. AA can be optimally treated by surgical excision while avoiding mutilating surgery. When complete resection is possible, it should be sought as it offers the lowest recurrence rate. AA is rarely life threatening and therefore partial resection is acceptable when high operative morbidity is anticipated. Regardless of whether the treatment is surgical, hormonal, or multimodal, it is clear that AA requires close and long-term follow up.

\section{Funding: No funding sources \\ Conflict of interest: None declared \\ Ethical approval: Not required}

\section{REFERENCES}

1. Steeper TA, Rosai J. Aggressive angiomyxoma of the female pelvis and perineum. Report of nine cases a distinctive type of gynecologic soft-tissue neoplasm. Am J Surg Pathol. 1983;7:463-75.

2. Han-Geurts IJ, van Geel AN, van Doorn L, den Bakker M, Eggermont AM, Verhoef C. Aggressive angiomyxoma: Multimodality treatments can avoid mutilating surgery. Eur J Surg Oncol. 2006;32:1217-21.

3. Dahiya K, Jain S, Duhan N, Nanda S, and Kundu P. "Aggressive angiomyxoma of vulva and vagina: a series of three cases and review of literature," Archiv Gynecol Obstetr. 2011;283(5)1145-8.

4. Dierickx I, Deraedt K, Poppe W, and Verguts J. Aggressive angiomyxoma of the vulva: a case report and review of literature. Archiv Gynecol and Obstet. 2008;277(6):483-7.

5. Kiran G, Yancar S, Sayar H, Kiran H, Coskun A, and Arikan DC. Late recurrence of aggressive angiomyxoma of the vulva. J Lower Genital Tract Disease. 2013;17(1):85-7.

6. Siassi RM, Papadopoulos T, Matzel KE. Metastasizing aggressive angiomyxoma. N Engl J Med. 1999;2:1772.

7. Haldar K, Martinek IE, Kehoe S. Aggressive angiomyxoma: a case series and literature review. Eur J Surg Oncol. 2010;36(4):335-9.

8. Outwater EK, Marchetto BE, Wagner BJ, Siegelman ES. Aggressive angiomyxoma: findings on CT and MR imaging. AJR Am J Roentgenol. 1999;172(2):435-8.

9. Htwe M, Deppisch LM, Saint-Julien JS. Hormonedependent, aggressive angiomyxoma of the vulva. Obstet Gynecol. 1995;86(4.2):697-9.

10. Fine BA, Munoz AK, Litz CE, Gershenson DM. Primary medical management of recurrent aggressive angiomyxoma of the vulva with a gonadotropinreleasing hormone agonist. Gynecol Oncol. 2001;81(1):120-2.

Cite this article as: Misra S, Rath TS, Nayak BL, Giri SK. Vulval angiomyxoma: a case report. Int J Reprod Contracept Obstet Gynecol 2017;6: 3692-4. 